Abstracted/indexed in Academic Search Complete, Agroforestry Abstracts, Asia Journals Online, Bangladesh Journals Online, Biological Abstracts, BIOSIS Previews, CAB Abstracts, Current Abstracts, Directory of Open Access Journals, EMBASE/Excerpta Medica, Google Scholar, HINARI (WHO), International Pharmaceutical Abstracts, Open J-gate, Science Citation Index Expanded, SCOPUS and Social Sciences Citation Index; ISSN: 1991-0088

\title{
Induction of cell death in prostate cancer cells by escopoletin, a promising treatment strategy
}

\author{
Da Chen', Xiao-Yi Zhang'ㄹ, Fa-Zhu Zheng3, Hai-Tao Wang', Jian-Liang Cai ${ }^{1}$ and Ming Xia' \\ ${ }^{1}$ Department of Urology, Beijing Shijitan Hospital, Capital Medical University. Beijing 100 038, China; ${ }^{2}$ Department \\ of Urology, The Second Artillery General Hospital PLA. Beijing 100 088, China; ${ }^{3}$ Department of Urology Handan \\ Peoples' Hospital, Handan 056 001, China.
}

\begin{tabular}{|c|c|}
\hline \multicolumn{2}{|l|}{ Article Info } \\
\hline $\begin{array}{l}\text { Received: } \\
\text { Accepted: } \\
\text { Available Online: }\end{array}$ & $\begin{array}{r}26 \text { April } 2015 \\
16 \text { May } 2015 \\
1 \text { July } 2015\end{array}$ \\
\hline \multicolumn{2}{|c|}{ DOI: 10.3329/bjp.v10i3.23095 } \\
\hline \multicolumn{2}{|c|}{$\begin{array}{l}\text { Cite this article: } \\
\text { Chen D, Zhang XY, Zheng FZ, Wang } \\
\text { HT, Cai JL, Xia M. Induction of cell } \\
\text { death in prostate cancer cells by esco- } \\
\text { poletin, a promising treatment strat- } \\
\text { egy. Bangladesh J Pharmacol. 2015; } \\
\text { 10: } 500-04 \text {. }\end{array}$} \\
\hline
\end{tabular}

Abstract
Escopoletin, a phenolic compound belonging to anthocyanin family shows
promising antioxidant activities. In the present study, anti-cancer effects of
escopoletin treatment in DU145 cells were investigated. The sulphorhoda-
mine-B staining and annexin V and propidium iodide were respectively used
for the analysis of cell viability and death. The results revealed a significantly
higher cytotoxicity by escopoletin that caused cell death in DU145 cells.
Escopoletin treatment in DU145 cells markedly inhibited cell growth through
non-apoptotic cell death and induced significant reactive oxygen species
(ROS) production. It also induced G1 cell cycle arrest and cyclin D1 accumu-
lation through the enhanced expression of p21. However, the effect of escopo-
letin on DU145 cells was reversed by pretreatment with glutathione antioxi-
dant. This suggests that escopoletin induced generation of ROS is responsible
for the increased cytotoxicity in DU145 cells. Thus, escopoletin exhibits
potential therapeutic efficacy for the treatment of prostate cancer.

\section{Introduction}

Prostate cancer constitutes the second leading cause of cancer deaths among the men belonging to North America and is the frequently detected cancer (Gro"nberg, 2003). The tumor is characterized by either slow growing indolent stage or an aggressive stage but both the stages are undifferentiable based on the use of current available methods. The biomarker usually employed for the prostate cancer is prostate-specific antigen but its level is enhanced in non-cancerous diseases as well (Diamandis, 1998; Sardana et al., 2008).

Flavonoids, found abundantly in plants exhibit positive effects on human health and show wide range of antibacterial, antiviral, anti-inflammatory, anti-cancer, and anti-allergic activities (Di Carlo et al., 1999; Montoro et al., 2005). Human body is supplied with the flavonoids in the form of different herbal drugs and related phytomedicines (Montoro et al., 2005). Flavonoids, belonging to phenolic family possess potent antioxidant activity and are highly effective scavengers of most oxidizing molecules, including singlet oxygen, and various free radicals (Bravo, 1998) implicated in several diseases. It is reported that phenolic compounds inhibit generation of reactive oxygen species (ROS) by suppressing the enzymes, scavenging reactive species and promoting antioxidant defenses (van Acker et al., 1996). Anthocyanins constitute largest group of phenolic compounds with promising antioxidant activities (Velioglu et al., 1998). The present study investigated the cytotoxic efficacy of the escopoletin in the prostate cancer cell line, DU145 and revealed its potential therapeutic efficacy in vivo. The human DU145 cells are androgen-independent and proliferate normally in androgen-deprived media.

\section{Materials and Methods}

Cell culture: The human DU145 cell line was purchased from American Type Culture Collection (ATCC). The 
cells were cultured in Dulbecco's modified Eagle's medium (DMEM) containing $10 \% \mathrm{FBS}$ at $37^{\circ} \mathrm{C}$ in an atmosphere containing $5 \% \mathrm{CO}_{2}$.

Cell viability assay: DU145 cells were seeded at a density of $2.5 \times 10^{5}$ per $100 \mu \mathrm{L}$ onto 96-well plates and incubated overnight, then assayed by sulphorhodamine-B staining. Absorbance was measured at $570 \mathrm{~nm}$ using an ELISA reader.

Cell cycle analysis: Propidium iodide staining (cycle test plus DNA reagent kit, BD Biosciences) was used for the analysis of cell cycle distribution according to manual protocol. The cells were then examined by flow cytometry (FACScan, BD Biosciences).

Western blot analysis: The cells were lysed in $20 \mu \mathrm{L}$ loading buffer (20\% glycerol, 2\% SDS, $125 \mathrm{mM}$ Tris $\mathrm{pH}$ $6.8,5 \% \beta$-mercaptoethanol, bromophenol blue) followed by incubation for $5 \mathrm{~min}$ at $95^{\circ} \mathrm{C}$. The $8-16 \%$ precise protein gel (Fisher Scientific, Schwerte, Germany) was used for the separation. The proteins were transferred onto PVDF membranes (GE Healthcare, Freiburg, Germany) and incubated with primary antibodies against GAPDH, p21 and cyclin D1 Santa Cruz Biotechnology Inc. (Santa Cruz, CA, USA). $\beta$-actin (Sigma-Aldrich, St. Louis, MO, USA) was used as loading control. The secondary polyclonal rabbit anti-mouse immunoglobulin or the polyclonal swine anti-rabbit immunoglobulin HRP-linked antibody and the enhanced chemiluminescence kit (GE Healthcare) were used for visualization.

Flow cytometric assessment of cell death using annexin $V / P I$ assay: The annexin V-FITC apoptosis detection kit (BD Bioscience, San Jose, CA, USA) was used to measure apoptosis in DU145 cell lines. The cells were incubated at a density of $2.5 \times 10^{5}$ cells/well for 24 hours followed by treatment with escopoletin for 48 hours. After treatment the cells were washed with PBS and then suspended in $100 \mu \mathrm{L}$ binding buffer. Incubation of cells with $3 \mu \mathrm{L}$ annexin V-FITC (BD Bioscience) was followed by addition of $10 \mu \mathrm{L}$ propidium iodide (BD Bioscience) at room temperature for $15 \mathrm{~min}$. Flow cytometry (Becton-Dickinson, San Jose, CA, USA) was used to determine the fluorescent intensities.

Intracellular ROS assays: A $5 \mu \mathrm{M}$ non-fluorescent probe, 2',7'-dichlorofluorescein-diacetate (DCFH-DA) was used for the detection of formation of ROS. The flow cytometry (FC500) was used to measure the fluorescence generated for oxidation of DCFH.

Statistical analysis: The MedCalc version 10.0 program (Frank Schoonjans, University of Gent, Belgium) was employed for the statistical analyses. The MannWhitney U-test, analysis of variance, and the KruskalWallis tests were used. The differences were considered statistically significant at $\mathrm{p}$ value $<0.05$.

\section{Results}

Escopoletin suppresses proliferation of DU145 cells: Investigation of the effect of escopoletin on DU145 cell sensitivity revealed inhibitory effect after 24 hours (Figure 1 ). The inhibitory effect of escopoletin was found to be dose dependent with maximum inhibition at $20 \mu \mathrm{M}$ after 24 hours. Although the inhibition of cell viability started at $5 \mu \mathrm{M}$ concentration of escopoletin but the effect was significant at $20 \mu \mathrm{M}$.

Escopoletin induces non-apoptotic cell death in DU145 cells: The results from flow cytometry showed an increase in the percentage of propidium iodide stained cells with increase in concentration of escopoletin from 5 to 20 $\mu \mathrm{M}$. The proportion of propidium iodide stained cells was found to be $1.7,19.6,25.8$ and $58.5 \%$, respectively at $0,5,10$ and $20 \mu \mathrm{M}$ after 24 hours of the treatment (Figure 2). However, there was no change in the

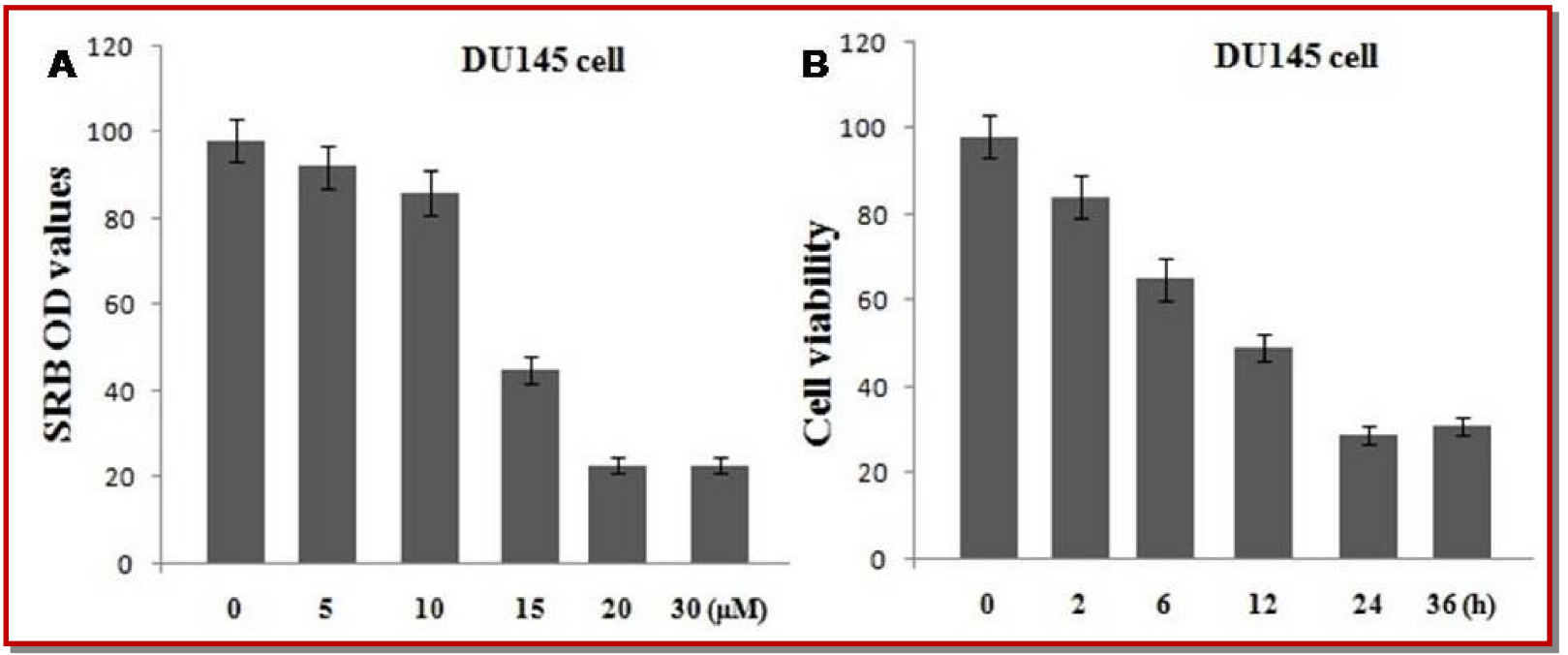

Figure 1: Inhibition of DU145 cell proliferation by escopoletin 


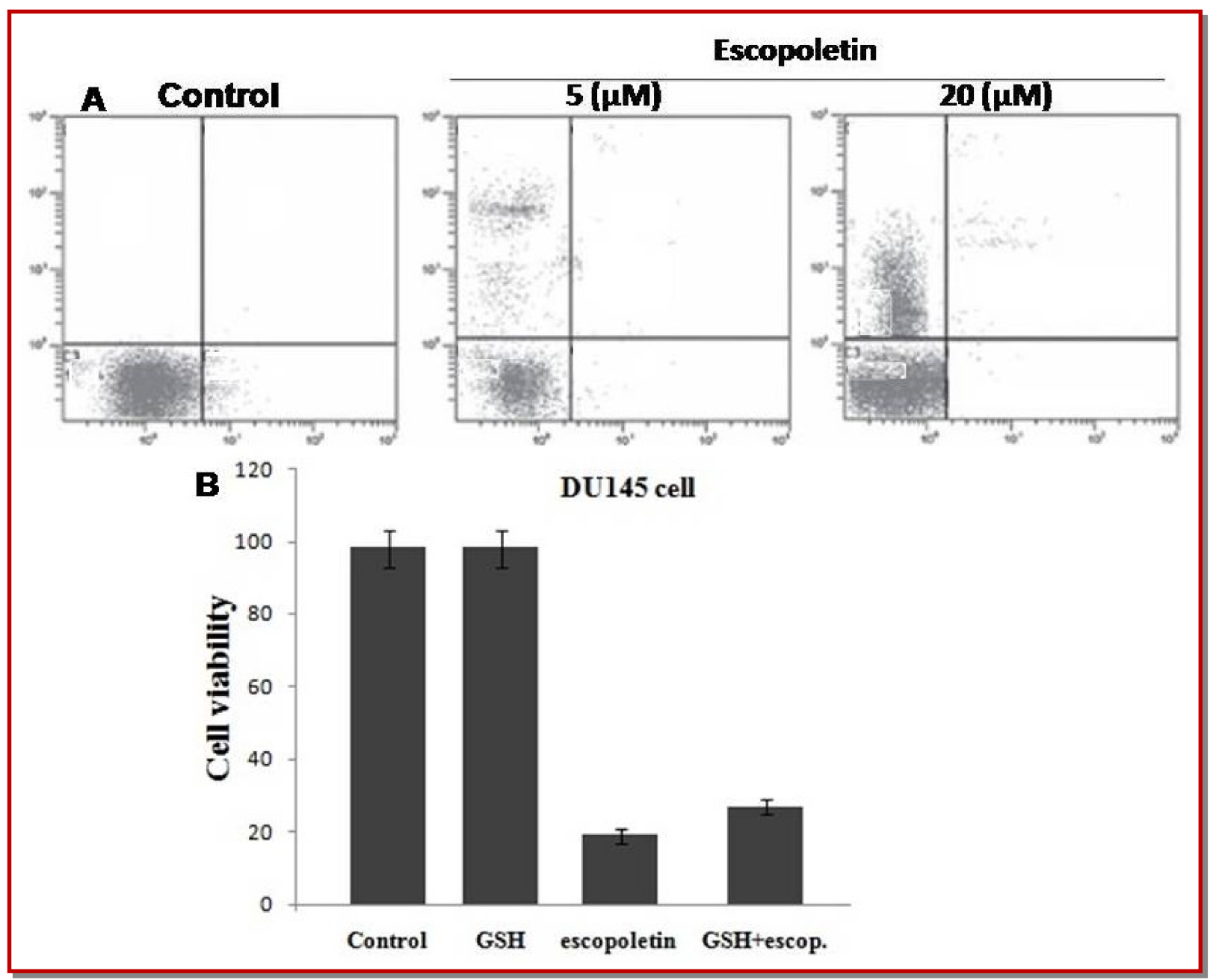

Figure 2: Induction of cell death and ROS generation in prostate cancer cells by escopoletin. DU145 cells were treated with the indicated concentrations of escopoletin for 24 hours in 6-well plates and the positive staining of cells by annexin $\mathrm{V}$ or propidium iodide binding was measured with flow cytometry

proportion of annexin V-stained cells with the increase in concentration of escopoletin. On the other hand, treatment of cells with $20 \mu \mathrm{M}$ of escopoletin showed appearance of many trypan blue stain-positive cells. Therefore, escopoletin treatment results in increase in the rate of non-apoptotic cell death.

Escopoletin induces generation of ROS in DU145 cells: Exposure of DU145 cells to $20 \mu \mathrm{M}$ escopoletin for 24 hours markedly enhanced the concentration of intracellular ROS (DCFH) compared to the untreated control cells. The level of ROS in DU145 cells was enhanced by 9-fold compared to untreated cells. However, the effect of escopoletin on DU145 cells was reversed in the cells pretreated with glutathione (GSH) antioxidant (Figure 3). This suggests that escopoletin induced generation of ROS is responsible for the increased cytotoxicity in DU145 cells.

Escopoletin regulates cell cycle in DU145 cells: The results from flow cytometry showed that escopoletin treatment at a dose of $20 \mu \mathrm{M}$ for 24 hours resulted G1 cell cycle arrest, decreased population of cells in the S and G2/M phases without any effect on sub-G1 cell population (Figure 3A). The cell cycle arrest of DU145 cells by escopoletin was found to be dose dependent. Exposure of DU145 cells to 10 and $20 \mu \mathrm{M}$ of escopoletin caused accumulation of 54.6 and $79.5 \%$ cells, respectively in the population of cells in G1 phase. Western blot analysis revealed enhanced expression of G1 phase marker, the cyclin D1 protein at a concentration of $20 \mu \mathrm{M}$ escopoletin in DU145 cells (Figure 3B).

\section{Discussion}

In the current study effect of escopoletin was investigated against prostate cancer cells. The results revealed that escopoletin inhibited the viability of DU145 cells in a dose dependent manner. It caused accumulation of cells in the G1 phase of cell-cycle and did not induce apoptosis. Analysis of the presence G1 phase marker in DU145 cells showed significantly higher concentration 

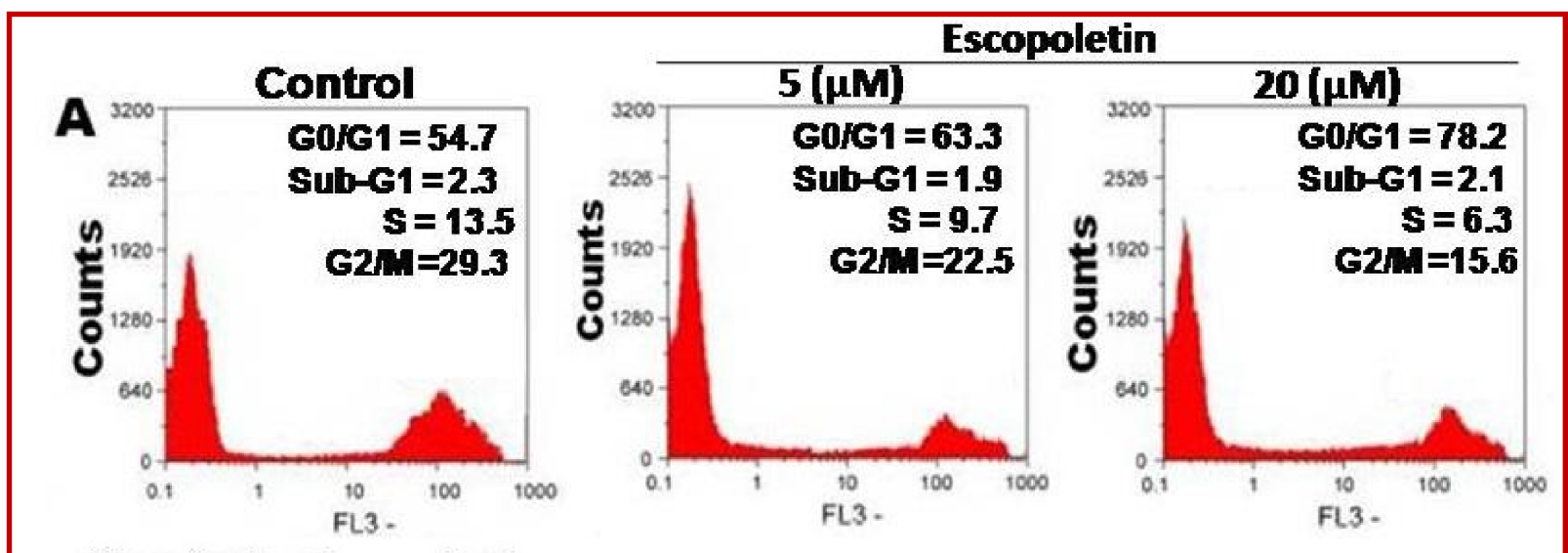

B Control Escopoletin

p21

GAPDH

Cyclin D1

GAPDH

Figure 3: Escopoletin-mediated cell cycle regulation in DU145 cells. (A) The percentage of cells in various phases was determined by flow cytometry. (B) Escopoletin-mediated cell cycle regulation molecules were also assayed. The DU145 cells were incubated in 6-well plates for 24 hours, then treated with $10 \mu \mathrm{M}$ DU145 for 24 hours. The cell lysates were analyzed with western blotting for p21 and cyclin D1. PI, propidium iodide

of the cyclin D1 protein. Escopoletin treatment also caused accumulation of p21 in DU145 cells. It is reported that $\mathrm{p} 21$ regulation is responsible for inhibition of various types of tumors (Abbas and Dutta, 2009). The results from our study revealed that escopoletin induces arrest of cell-cycle in G1 phase through the involvement of p21. The flow cytometry showed an increase in the percentage of propidium iodide stained cells with increase in concentration of escopoletin. The ratio of non-apoptotic cell death in the annexin $\mathrm{V} /$ propidium iodide double-staining assay was consistent with the sulphorhodamine-B cell viability induced by escopoletin treatment. The results also revealed that no significant early apoptosis was caused by escopoletin. It has been observed in the primary rat cortical neurons that a reduction in the level of GSH is dependent on the enhancement in oxidative stress (Hood et al., 2010). Generation of ROS has been observed before the onset of cell death and its increased generation in necrosis is responsible for cell death (Di Stefano et al., 2006). Our results showed that escopoletin treatment resulted in the generation of ROS which in turn induced nonapoptotic cell death in DU145 cells. However, exposure of DU145 cells to GSH reversed the anti-cancer effect induced by escopoletin. This suggests that escopoletin exhibits its effect on prostate cancer cells through production of ROS. The present study demonstrates that escopoletin treatment can be potential anticancer agent against prostate cancer.

\section{References}

Abbas T, Dutta A. p21 in cancer: Intricate networks and multiple activities. Nat Rev Cancer. 2009; 9: 400-14.

Bravo L. Polyphenols: Chemistry, dietary sources, metabolism and nutritional significance. Nutr Rev. 1998; 56: 317-33. 
Diamandis EP. Prostate-specific antigen: Its usefulness in clinical medicine. Trends Endocrinol Metab. 1998; 9: 310-16.

Di Carlo G, Mascolo N, Izzo AA, Capasso F. Flavonoids: Old and new aspects of a class of natural therapeutic drugs. Life Sci. 1999; 65: 337-53.

Di Stefano A, Frosali S, Leonini A, Ettorre A, Priora R, Di Simplicio FC, Di Simplicio P. GSH depletion, protein S-glutathionylation and mitochondrial transmembrane potential hyperpolarization are early events in initiation of cell death induced by a mixture of isothiazolinones in HL60 cells. Biochim Biophys Acta. 2006; 1763: 214-25.

Gro“nberg, H. Prostate cancer epidemiology. Lancet 2003; 361: 859-64.

Hood JE, Jenkins JW, Milatovic D, Rongzhu L, Aschner M. Mefloquine induces oxidative stress and neurodegeneration in primary rat cortical neurons. Neurotoxicology 2010; 31: 518-23.

Montoro P, Braca A, Pizza C, De Tommasi N. Structureantioxidant activity relationships of flavonoids isolated from different plant species. Food Chem. 2005; 92: 349-55.

Sardana G, Dowell B, Diamandis EP. Emerging biomarkers for the diagnosis and prognosis of prostate cancer. Clin Chem. 2008; 54: 1951-60.

van Acker SABE, van den Berg DJ, Tromp MNJL, Griffioen $\mathrm{DH}$, van Bennekom WP, van der Vijgh WJF, Bast A Structural aspects of antioxidant activity of flavonoids. Free Radic Biol Med. 1996; 20: 331-42.

Velioglu YS, Mazza G, Gao L, Oomah BD. Antioxidant activity and total phenolics in selected fruits, vegetables and grain products. J Agric Food Chem. 1998; 46: 4113-17.

\section{Do you want to publish?}

Your research methodology as video file in

Bangladesh Journal of Pharmacology

Author Info

Ming Xia (Principal contact)

e-mail: xiaming426@gmail.com; Tel \& fax: 0086-010-63926186

First two authors contributed equally 